\title{
1817-2017: Générations Staël
}

\section{Michel Arrous}

\section{(2) OpenEdition}

\section{Journals}

\section{Édition électronique}

URL : http://journals.openedition.org/studifrancesi/16473

DOI : 10.4000/studifrancesi. 16473

ISSN : 2427-5856

\section{Éditeur}

Rosenberg \& Sellier

\section{Édition imprimée}

Date de publication : 1 juillet 2019

Pagination : 170

ISSN : 0039-2944

\section{Référence électronique}

Michel Arrous, « 1817-2017: Générations Staël », Studi Francesi [En ligne], 187 (LXIII | I) | 2019, mis en ligne le 01 juillet 2019, consulté le 25 janvier 2021. URL : http://journals.openedition.org/studifrancesi/ 16473 ; DOI : https://doi.org/10.4000/studifrancesi.16473

Ce document a été généré automatiquement le 25 janvier 2021.

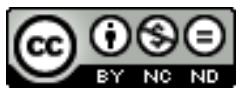

Studi Francesi è distribuita con Licenza Creative Commons Attribuzione - Non commerciale - Non opere derivate 4.0 Internazionale. 


\title{
1817-2017: Générations Staël
}

\author{
Michel Arrous
}

\section{RÉFÉRENCE}

1817-2017: Générations Staël, «Cahiers staëliens», nouvelle série, 67, Paris, Champion Genève, Slatkine, 2017, 379 pp.

1 Comme le mentionne Stéphanie GENAND en présentant ce numéro du bicentenaire, la recherche staëlienne a évolué ces dernières années; toutefois préjugés et stéréotypes persistent que s'emploient à réduire de jeunes chercheurs.

2 La première partie intitulée "Génération Staël» regroupe trois figures majeures du cercle staëlien. Catherine DUBEAU présente, analyse et publie les écrits que rédigea le père de Germaine après la mort de son épouse (Écriture intime et ambivalence du deuil dans deux inédits de Jacques Necker: "Confortation against me" et "Pour moi, her merits", pp. 13-43). On sera frappé par l'intensité passionnelle du premier et, dans le second, par un portait infiniment sensible de la défunte. Quant à Albertine que Lamartine voyait comme «une Corinne religieuse, modeste, sainte», Susanne HILMANN la comprend à la lumière de Mélanie Klein ("C'est une grande difficulté que d'être la fille de Madame de Staël»: Albertine de Broglie and the mother-daughter knot, pp.45-65), où l'on voit que le conflit entre mère et fille ne se réduisait pas à un simple manque d'affection. Dans cette «singulière famille», un autre cas troublant, celui du dernier mari de Mme de Staël, mort autant de phtisie que de nostalgie, examiné par Stéphanie GENAND (Pathologies de la mémoire: le cas John Rocca, pp. 67-76). L'analyse s'appuie sur Le Mal du pays, manuscrit inachevé de 1817-1818 qui est une confession biographique sous le voile de la fiction.

Dans la deuxième partie, "Générations staëliennes», la section «Retours» retrace le parcours de quelques membres éminents du groupe de Coppet. Lucien JAUME (Germaine de Staël, une source jamais tarie pour notre temps, pp. 81-100) passe en revue les apports neckeriens, staëliens et constantiens au libéralisme français. Ce qui distingue Mme de Staël de toutes les femmes de la Révolution et de l'Ancien Régime, c'est bien sûr le talent de la parole qui la place au premier rang sur le «théâtre du monde», talent dont 
Geneviève FRAISSE repère les effets dans le discours intime, à partir d'une remarque de Michelet dans Les Femmes de la Révolution: Les "monologues éloquents" (pp. 101-111). Si, il y a trente ans, lire Corinne avec Juliette tenait sans doute de la provocation, il en va autrement aujourd'hui, aussi Michel DELON revient-il sur les points de rencontre, voire la parenté structurelle des deux univers romanesques (Staël, Sade et le dépassement de soi, pp. 113-130). On a droit à une belle illustration des études coppétiennes avec l'Itinéraire d'un neckerien (pp. 131-135), à savoir celui de l'historien Léonard BURNAND qui a consacré une bonne part de ses travaux à la success story de Jacques Necker et qui entretient sa gloire, jusqu'à parfois passer pour son héros. On sait que Mme de Staël avait rédigé un dénouement entièrement nouveau pour son premier roman publié en 1820 par Auguste de Staël sans renoncer au précédent. C'est sa genèse que Catriona SETH retrace dans Finir "Delphine" (pp. 137-152). En dépit d'importants travaux universitaires, force est de reconnaître qu'à certains égards, par exemple son adhésion républicaine et son rapport à l'activité politique, la «vraie femme politique» que fut, selon M. Winock, Mme de Staël pourrait être mieux servie. Florence LOTTERIE explore les causes de cette lacune depuis les années 1980 dans Un effort pour rester républicaine. Germaine de Staël, l'énergie du «centre» (pp.153-173). De cette relecture critique, il ressort que la théorie de la conciliation, avec l'idée du «troisième parti» (expression de Mme de Staël dans les années 1795-1799), est au cœur de son discours et la sépare des réactionnaires. Féministe de longue date, Madelyn GUTWIRTH commente le choix qu'elle fit de s'intéresser au début des années 1960 à Mme de Staël, dont elle donna un premier témoignage en 1978 avec Mme de Staël, Novelist - The Emergence of the Artist as Woman. Suivirent de nombreuses études orientées par le souci de comprendre la place de Staël dans la lutte des femmes pour obtenir le droit à la parole et ne pas être cantonnées ou réduites, comme le voulait Rousseau, au rôle d'amante et de mère (Entre la honte et la jubilation: Notes sur une vie staëlienne, pp. 175-186). La deuxième section, «État des lieux», propose trois riches dossiers: Stéphanie GENAND parcourt Cent ans d'études staëliennes (pp. 189-203), Catherine DUBEAU dresse un Bilan critique de la recherche actuelle sur Jacques et Suzanne Necker (pp. 205-235), Aline HODROGE et Blandine POIRIER ont établi une Bibliographie staëlienne (2006-2017) (pp. 237-278). Dans «Horizons», la troisième section, Fanny ARAMA illustre La réception conservatrice de Germaine de Staël dans la seconde moitié $d u$ XIXe

siècle: le cas de Jules Barbey d'Aurevilly et de Léon BloyLes Bas-bleusDe la littératureDe l'AllemagneCorinneBROCCARDO(«Indignez-vous!» Considérations staëliennes sur l'histoireHODROGE(«Être un quart d'heure un autre»: sympathie et théâtre staëlienMORINEntre proximité et distance: la lecture staëlienne sous le signe du malentenduXVIII ${ }^{\mathrm{P}}{ }^{\mathrm{PIRIER}}$ «Dompter le caractère»: enfance et éducation dans les nouvelles et romans de G. de Staël 